\title{
AMCOR
}

Asahikawa Medical College Repository http:/lamcor.asahikawa-med.ac.jp/

Anaesthesia. (2007) 62(7): 746-747.

Airtraq ${ }^{\circledR}$ for awake tracheal intubation.

Suzuki A, Toyama Y, Iwasaki H, Henderson J. 


\section{Airtraq $^{\circledR}$ for awake tracheal intubation}

The Airtraq (Prodol Meditec S.A., Vizcaya, Spain) is a new single-use tracheal intubation device which is passed over the dorsum of the tongue to provide an indirect view of the glottis without the need to achieve a direct line of sight by conventional use of the 'sniff' position and displacement of the tongue to the left. Because the tongue is not displaced and forceful elevation of the epiglottis is not required, the Airtraq probably requires less force to be applied than during conventional direct laryngoscopy [1]. It should therefore be suitable for awake intubation. We used the Airtraq for awake tracheal intubation of an elderly woman with gastro-oesophageal regurgitation after previous proximal gastrectomy and was scheduled for residual gastrectomy. She had a known history of difficult laryngoscopy (Cormack \& Lehane grade 3). A rapid sequence technique with cricoid pressure was not attempted because she was at risk of regurgitation in the presence of difficult intubation. Therefore, awake intubation was scheduled. The patient's oral cavity was topicalised with lidocaine $8 \%$ spray before intubation was attempted. An initial attempt with the conventional Macintosh blade was unsuccessful because laryngoscopy was difficult and poorly tolerated due to an active gag reflex. An attempt was next made with the Airtraq with some modification of the device (Figure 1). The tracheal tube was placed in the side channel of the airtraq and connected to the respiratory circuit via a Bodai Suction Safe ${ }^{\circledR}$ swivel Y-connector 
(Sontec Medical, Massachusetts, USA). Oxygen at $10 \mathrm{l} \cdot \mathrm{min}^{-1}$ was administered to prevent both desaturation of the patient and to reduce the risk of fogging of the blade-tip lens during the intubation procedure. Excessive saliva in the oropharynx was removed under vision via a 14 Fr suction catheter inserted through the tracheal tube via the Bodai connector. Visualization of the patient's vocal cords was achieved easily, the percentage of glottic opening (POGO) score [2] being 70\%. After additional topical anesthesia was applied to the vocal cords with a tracheal spray tube the patient's trachea was intubated uneventfully at the first attempt. We conclude that the Airtraq with the modifications described above can be a useful and well-tolerated device in management of patients who require awake tracheal intubation.

\section{A. Suzuki}

Y. Toyama

H. Iwasaki

Asahikawa Medical College,

Hokkaido 078-8510, Japan

E-mail masuikasuzuki@yahoo.co.jp

\section{J. Henderson}

Gartnavel General Hospital, 
Glasgow, UK.

\section{References}

1 Maharaj CH, O'Croinin D, Curley G, Harte BH, Laffey JG. A comparison of tracheal intubation using the Airtraq ${ }^{\circledR}$ or the Macintosh laryngoscope in routine airway management: a randomized, controlled clinical trial. Anaesthesia 2006; 61: $1093-9$

2 Ochroch EA, Hollander JE, Kush S, et al. Assessment of laryngeal view: percentage of glottic opening score vs. Cormack and Lehane grading. Canadian Journal of Anesthesia 1999; 46: 987-90. 


\section{Legend}

Figure 1

Modification of the Airtraq for awake intubation (1. Airtraq ${ }^{\circledR}$, 2. Bodai Suction Safe ${ }^{\circledR}$ swivel Y-connector, 3. 14Fr suction catheter, 4. tip of suction catheter, 5. breathing circuit)

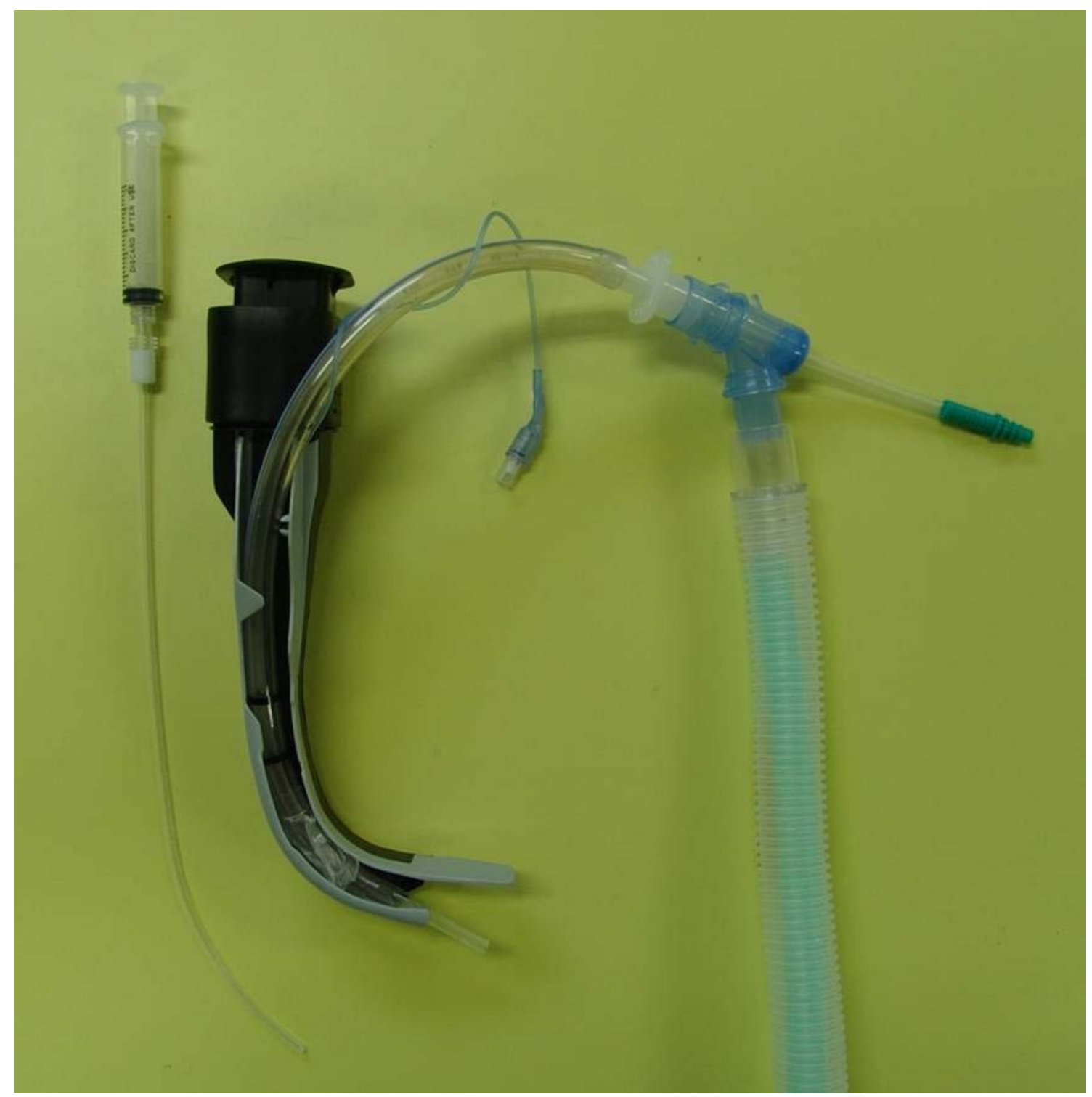

